\title{
A socio-ecological perspective on behavioural interventions to influence food choice in schools: alternative, complementary or synergistic?
}

\author{
Laurence Moore $^{1, *}$, Andrea de Silva-Sanigorski ${ }^{2}$ and Sue N Moore ${ }^{1}$ \\ ${ }^{1}$ DECIPHer UKCRC Public Health Research Centre of Excellence, Cardiff School of Social Sciences, Cardiff \\ University, 1-3 Museum Place, Cardiff CF10 3BD, UK: ${ }^{2}$ Jack Brockhoff Child Health \& Wellbeing Program, \\ The McCaughey Centre, Melbourne School of Population Health, University of Melbourne, Melbourne, \\ Victoria, Australia
}

Submitted 13 April 2012: Final revision received 18 October 2012: Accepted 6 December 2012: First published online 4 March 2013

\begin{abstract}
Objective: An increasing focus on legislation, policy and guidance on the nutritional content of school food has in part been in response to the limited impact of more behavioural or educational approaches. However, there is a risk that a sole focus on policy-level action may lead to neglect of the important contribution that more behavioural approaches can make as components of effective, coordinated, multilevel action to improve the dietary intake of schoolchildren. The current paper aims to highlight the potential importance of viewing alternative approaches as complementary or synergistic, rather than competing.

Design: The socio-ecological and RE-AIM frameworks are used to provide a theoretical rationale and demonstrate the importance of explicitly identifying the interdependence of policies, interventions and contextual structures and processes. School food case study evidence is used to exemplify how understanding and exploiting these interdependencies can maximise impact on dietary outcomes.

Setting: Case studies of trials in schools in the UK (South West England and Wales) and Australia (Victoria).

Subjects: Schoolchildren.

Results: The case studies provide examples to support the hypothesis that the reach, effectiveness, adoption, implementation and maintenance of school food policies and interventions can be maximised by understanding and exploiting the interdependence between levels in the socio-ecological framework.

Conclusions: Rather than being seen as competing alternatives, diverse approaches to improving the diets of schoolchildren should be considered in terms of their potential to be complementary and synergistic, acting at multiple levels to improve acceptability, fidelity, effectiveness and sustainability.
\end{abstract}

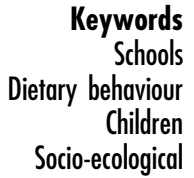

The majority of interventions which aim to alter food choice and related behaviours have been developed using principles from health psychology and health education, with interventions largely targeted at the individual. Over time, these interventions have become more sophisticated, moving from a relatively simplistic model in which behaviour was largely determined by knowledge and attitudes, towards theories and concepts including social cognitive theory, the transtheoretical model and health literacy ${ }^{(1)}$. However, it has been increasingly recognised that food choice and consumption are strongly influenced by a range of other factors operating at multiple levels of influence across domains including the environment, social context, policy and culture ${ }^{(2,3)}$. In the current paper, socio-ecological and RE-AIM frameworks are used to highlight the importance of recognising intrapersonal, interpersonal, organisational/settings, community, environment and political influences, and their interactions, in developing effective and sustainable solutions to improving children's dietary intake in schools. Evidence to support this approach is presented, with a focus on selected recently published studies that highlight the importance of understanding how interactions between levels can undermine or magnify intended intervention effects.

\section{Theoretical frameworks}

\section{Multilevel perspectives}

One of the most frequently cited taxonomies of the multiple levels of influence on health is that of Whitehead, 
who identifies: (i) individual lifestyle factors; (ii) social and community networks; (iii) living and working conditions; and (iv) socio-economic, cultural and environmental conditions ${ }^{(4)}$. In discussing actions that might be taken to tackle social inequalities in health, Whitehead largely presents actions at each level as alternatives, although she notes that causes of social inequality in health are multiple and interrelated, and that actions need to be interconnected across intervention levels.

\section{Too often a bipolar debate}

However, all too often, the potential methods to improve health, including children's dietary intake in schools, are presented as alternatives, requiring policy makers to choose between competing approaches such as: behaviour change or health determinants?, individual focus or population health?, influencing choice or legislation? Criteria that might help determine which of the alternatives to choose are also highly contested on various grounds including politics, values, ethics, strength of evidence and epistemology. For example, the Nuffield Council on Bioethics considered the relative merits of influencing choice or legislation, largely on the basis of the potential infringement of free choice associated with legislation and the perceived coercion associated with the pejorative term 'nanny state ${ }^{,(5)}$. Although the report makes a strong case for higher-level actions and the need for both the state and the individual to take responsibility, it is best known for identifying a ladder of interventions of increasing coercion and for recommending that stronger evidence of effectiveness is needed to justify more intrusive policies and actions; a call that is often used as an argument against legislative approaches.

'Nudge' has become a popular approach, based on behavioural economics in which the choice environment is modified to either overtly or, more often, unobtrusively encourage or discourage individuals' behaviour ${ }^{(6)}$. This may, for example, be through financial or other incentives, or through modifying the physical environment or social norms. Nudging has not been clearly defined yet tends to exclude informing individuals and certainly excludes the elimination of choice through legislation. Commentators have criticised 'nudge' for acknowledging the importance of the choice environment yet ruling out legislative actions, which can often be the most powerful way of modifying the attractiveness of alternative choices ${ }^{(7,8)}$.

\section{Socio-ecological framework}

The socio-ecological health promotion framework proposed by McLeroy and colleagues ${ }^{(9)}$ is based upon ecological systems theory (EST), which espouses that human development is shaped by a number of systems or contexts ${ }^{(10,11)}$. These include: the immediate settings in which an individual participates (e.g. home, school, workplace) and relationships within and between them; relationships between settings in which the individual person does not
Table 1 The socio-ecological framework ${ }^{(9)}$

\begin{tabular}{ll}
\hline Level of change & Approach and target \\
\hline Intrapersonal & $\begin{array}{c}\text { Individual characteristics that influence } \\
\text { behaviour such as attitudes and beliefs } \\
\text { Interpersonal and group influences such as } \\
\text { social networks and social support } \\
\text { Interpersonal } \\
\text { Rules, regulations, policies and ethos that } \\
\text { may promote or endanger health }\end{array}$ \\
$\begin{array}{l}\text { Organisational } \\
\text { Community } \\
\text { policy }\end{array}$ & $\begin{array}{c}\text { Policies, advocacy, environments and } \\
\text { structures that impact on health }\end{array}$ \\
\hline
\end{tabular}

participate but which affect the immediate environment (e.g. the education system); and generalised patterns that define the substance and structure of other systems (e.g. societies, social groups) but which are modifiable (e.g. by public policy). The McLeroy framework identifies multiple, interdependent leverage or evaluative points at policy, community, organisational, interpersonal and intrapersonal levels (see Table 1) and has been recommended as a theoretical, methodological and evaluative tool capable of supporting a consistent, holistic approach during the design, implementation and evaluation of health improvement interventions ${ }^{(12)}$. The socio-ecological framework encourages both whole-system interventions, such as promoted by the settings approach to health promotion, and also the explicit understanding of how more focused interventions might depend on factors at other levels for their effectiveness, acceptability or sustainability to be achieved.

Schools have been recognised as health promotion settings since the 1986 Ottawa Charter ${ }^{(13)}$. Health-promoting schools operate at many socio-ecological levels by promoting the health of the staff, families, communities and pupils associated with them ${ }^{(14)}$. However, school-based health promotion initiatives have not always encompassed all the levels within EST in that they frequently incorporate processes within and between the most proximal levels (e.g. classroom, home or community) ${ }^{(15)}$ but exclude policy contexts ${ }^{(16)}$. Similarly, policy has not always accounted for all influences within the EST model ${ }^{(17)}$ and policy evaluations have generally failed to recognise the multilevel complexity inherent within a health-promoting school ${ }^{(15,16)}$. Thus, the complementary or synergistic capability of the socio-ecological framework has rarely been fully exploited.

There has recently been an emphasis on extending socio-ecological thinking into systems approaches, which attempt to map the interactions between multiple system components at multiple levels. Although detailed and complex, system maps (and sub-system maps) have been used effectively in tobacco control and increasingly in obesity prevention to identify the best points for intervention and the potential likely impacts ${ }^{(18)}$. In addition, system mapping can be used to determine points for evaluation and where effective intervention components can be embedded to alter the system for long-term, sustainable change. 


\section{RE-AIM}

Glasgow and co-workers' RE-AIM framework ${ }^{(19)}$ highlights the need for policies and interventions to not only be evaluated in terms of their effectiveness in a research setting or other idealised circumstances, but to recognise that considerations of reach, adoption, implementation and maintenance are also critically important in determining whether they will produce the desired impacts in the 'real world'. Widening the lens to include these other aspects necessarily involves a multilevel perspective in which the interactions between all five levels of the socio-ecological framework are considered. This framework captures the following elements:

1. Reach: the proportion of the target group that the intervention reached.

2. Efficacy: the success rate (biological, behavioural and quality-of-life outcomes).

3. Adoption: the settings that adopt a policy or programme.

4. Implementation: the extent to which the intervention is implemented as intended.

5. Maintenance: the extent to which a programme is sustained over time.

The RE-AIM framework particularly recognises intervention delivery and acceptability and contextual variables as being crucial for adoption, implementation and maintenance of interventions, and as such ensures that the structures, processes and agents required to adopt, implement and maintain interventions are included in any assessment of an intervention's success. Thus, the professionals, communities, organisations, policies and contextual factors that may have an important role in determining the long-term real-world effectiveness of an intervention are considered in intervention design, theory and evaluation.

\section{Evidence to support a socio-ecological approach}

Socio-ecological perspectives and the RE-AIM framework determine that the core question when evaluating interventions that are complex and multilevel is not simply to ask 'what works?', but to ask 'what works, for whom, under what circumstances and why?' ${ }^{,(20)}$. The following case studies have used this broader research question to identify the importance of understanding and exploiting processes at multiple levels and their interactions. The case studies each demonstrate key specific issues that emerge from a multilevel approach to school food.

\section{The importance of engaging the whole school community to identify effective and sustainable programmes}

In 2002, the Sentinel Site for Obesity Prevention was established $^{(21)}$ as a demonstration site in the Barwon South West region of Victoria, Australia, that aimed to develop the programmes, skills and evidence necessary to attenuate and eventually reverse the obesity epidemic in children and adolescents. Three intervention projects were implemented and evaluated, and although each targeted different age groups (pre-school: 2-5 years; primary school: 5-12 years; secondary school: 13-17 years), they were developed with consistent theoretical approaches including social determinants of health, community participation and ownership, community capacity building and the socio-ecological framework. As a consequence, the interventions were implemented in multiple settings and had a focus on policy and environmental changes, with complementary behaviour change strategies also developed and implemented. The ANGELO framework (Analysis Grid for Elements Linked to Obesity) was utilised to enable communities and stakeholders to specify the targets for the policy and environmental changes ${ }^{(3)}$. The development of the specific intervention strategies and capacity-building components were also guided by the principles of the Ottawa Charter and the Jakarta Declaration. Further, the strategies and approaches were developed to be flexible, cost-effective, sustainable, equitable and safe.

This approach has proved extremely effective in developing community capacity to address childhood obesity in each of the three interventions, and has also been shown to reduce the risk of childhood obesity and create environmental changes in the target populations and communities involved ${ }^{(22-27)}$. The approach was not just focused on school foods, but to improve dietary patterns overall.

Looking specifically at the two school-based interventions, 'Be Active, Eat Well' (BAEW) in primary schools and 'It's Your Move!' (IYM) in secondary schools, the strategies implemented were multilevel, with activities targeting a mix of top-down (school policies and guidelines) and bottom-up (individual behaviour) changes. Examples from BAEW include: media, promotional materials and resources (e.g. water bottles, stickers), 'taste tests' for children, curriculum sessions, parent tip sheets and a parenting programme, but also school food policy changes, school support by the community dietitian, professional development for canteen managers, teacher information sessions, promotional activities in local food stores; community events; and inclusion of BAEW activities in local government planning documents. During the development and implementation of BAEW, various stakeholders were engaged at a number of levels and a comprehensive social marketing campaign was implemented. Social marketing principles were used to target decision makers and implementation staff with the intent of having them influence the social determinants of health and the target audience by 'selling' the personal, social and environmental benefits of change ${ }^{(21)}$. Local implementation, management and reference committees were also formed to implement the intervention with these committees providing decision making, administrative support and project advice, respectively. The BAEW 
intervention resulted in significant improvements at all levels of the intervention: increases in the community's capacity to provide a cohesive and sustained approach to obesity prevention; improved school environments and policies; and improvements in a variety of nutrition and physical activity behaviours and anthropometric outcomes (significantly smaller increases in weight (1 kg less) and waist circumference $(3 \mathrm{~cm}$ less)) over the 3-year intervention period when compared with control schools ${ }^{(27)}$. Importantly, the intervention impacts were greater in children from more disadvantaged households, there was no evidence of harm ${ }^{(27)}$ and the programme was cost-effective ${ }^{(28)}$.

A similarly multi-faced approach was taken in IYM, developed to test the effectiveness of a multi-faceted, multi-site, community-based intervention to reduce adolescent overweight and obesity by building community capacity to promote healthy eating and physical activity. Although similar in approach to the BAEW project, the strategies implemented in IYM were more 'peer-led' and age appropriate, delivered in schools through school project officers and student ambassadors. Specific examples include: capacity building among school project officers and student ambassadors (workshops and training opportunities); social marketing to increase awareness of project messages (student logo development and branding); promoting water and reducing soft drink consumption through distribution of refillable water bottles, school water polices, installation of new water fountains and removal of soft drinks from vending machines; promoting healthy breakfasts through school breakfast programmes; promoting fruit and vegetable consumption through soup days, juice days, vegetable gardens and social marketing; enhancing the nutritional quality of school foods using a traffic light system for food sold through school canteens, recipe books provided to canteen managers, healthy eating days, parent information sessions and canteen staff training; promoting active transport to/from school with riding to school programmes; increasing participation in organised sports and other active recreation (professional development for physical education teachers, lunchtime activities, education sessions and sports-related excursions); and promoting healthy body size and shape with body image training and education strategies ${ }^{(26)}$. The intervention was effective and resulted in significant differences in weight $(-0.74 \mathrm{~kg})$ and standardized BMI Z-scores (-0.07) between the intervention and comparison groups ${ }^{(26)}$.

\section{Policies or actions taken at one level may not produce the intended outcomes due to factors at other levels that mediate the relationship between the intervention and the outcome, and/or modify the anticipated effect, so that its effect is variable} Although this has been well established in the case of educational interventions, where, for example, efforts to educate children to eat more fruit can be undermined by the lack of access to fruit in school, another example is of a policy-level intervention, UK school food policy. Research into the socio-ecological processes associated with school-meal nutrition content legislation has highlighted the importance of attending to lower-level factors in order to effectively change what children eat ${ }^{(29-31)}$. In this case, local and school policies, while reflecting the primary objective of national policy with respect to the nutritional content of the school meal, are also influenced by multiple, competing interests including parental views, children's food preferences and organisational objectives such as protecting school meal uptake ${ }^{(30)}$. Tensions exist such that menus incorporating choices based on children's preferences can be viewed as facilitating service viability and prioritised over the promotion of healthy eating.

This research also highlights the role of school catering staff as the final arbiters regarding the food actually served to children since their individual working practices and beliefs influence the food available ${ }^{(30)}$. For example, the menu on offer in a particular school on a particular day not only reflects the various policy decisions that precede it, but also a range of practical decisions made by the cook-in-charge (e.g. the selection of 'seasonal' vegetables). Catering staff have been found to use different approaches to encourage children to choose menu items ${ }^{(30)}$ reflecting the personal styles, beliefs and experiences of staff rather than being disseminated in formal policies or training programmes. These staff feeding strategies are influenced by the constraints and opportunities offered by dining halls ${ }^{(31)}$, each of which has numerous generic attributes ${ }^{(29)}$ that have a direct, but not necessarily positive, bearing on food choice and consumption. Overcrowded, multi-purpose dining halls coupled with time pressures and dynamic social situations (e.g. discipline issues) detract from the eating experience and the ability of staff to encourage children to eat.

The researchers ${ }^{(29-31)}$ argue for complementary and synergistic actions at multiple levels to improve acceptability, implementation fidelity and behaviour change. In this case, a reorganisation of school meal providers, school cooks, lunchtime supervisors and pupils, and the development of strategic partnerships to minimise tensions between improved nutritional standards and school meal uptake, are recommended.

\section{The more schools do, the better the outcomes}

In an analysis of the diets of nearly 7000 children in sixtyfour secondary schools in Wales, UK, it was found that the number of actions that schools have in place to promote healthy eating is significantly associated with healthy food choices made by students ${ }^{(32)}$. This supports the notion that individual actions that schools can take should not be viewed as alternatives, but complementary and reinforcing. Further analysis of the same data found that interpersonal, school and community factors were the most significant in explaining variation in students' dietary behaviour and that actions at multiple levels acted synergistically ${ }^{(33)}$. 


\section{Multiple interventions can be synergistic}

Increasing access to healthier choices may not work on its own, yet in combination with policies to restrict the availability of other less healthy foods in schools, strong effects may be achieved. This was found in the case of fruit tuck shops, where twenty-three schools randomised to introduce fruit tuck shops did not, on average, see an increase in students' fruit consumption compared with twenty schools without fruit tuck shops. Yet in those schools where there were also policies to restrict unhealthy snacks in schools, there was a significant increase in fruit consumption and increased awareness of friends' fruit consumption $^{(34)}$.

\section{Conclusion}

The case studies provide examples to support the application of socio-ecological thinking in identifying comprehensive and effective action to improve the diets of schoolchildren. In particular, the case studies identified that the long-term effects of policies and interventions in real-world implementation can depend hugely on mediators and moderators acting at different levels. This can increase effectiveness and also maximise acceptability, adoption and maintenance within the school system. Policy makers and health promotion practitioners are encouraged to identify complementary or, ideally, synergistic policy components at multiple levels, rather than adopting an exclusive focus on intervening at any one of the levels of influence on dietary behaviour.

\section{Acknowledgements}

Sources of funding: The work was undertaken with the support of The Centre for the Development and Evaluation of Complex Interventions for Public Health Improvement (DECIPHer), a UKCRC Public Health Research: Centre of Excellence. Funding from the British Heart Foundation, Cancer Research UK, the Economic and Social Research Council (RES-590-28-0005), the Medical Research Council, the Welsh Government and the Wellcome Trust (WT087640MA), under the auspices of the UK Clinical Research Collaboration, is gratefully acknowledged. Conflicts of interest: There are no conflicts of interests associated with this work. Ethics: Ethical approval was not required. Authors' contributions: All authors contributed to the text of the article.

\section{References}

1. Glanz K, Rimer BK \& Lewis FM (editors) (2002) Health Behavior and Health Education: Theory Research and Practice, 3rd ed. San Francisco, CA: Jossey-Bass.

2. Brug J, Kremers SP, Lenthe FV et al. (2008) Environmental determinants of healthy eating: in need of theory and evidence. Proc Nutr Soc 67, 307-316.
3. Simmons A, Mavoa HM, Bell AC et al. (2009) Creating community action plans for obesity prevention using the ANGELO (Analysis Grid for Elements Linked to Obesity) Framework. Health Promot Int 24, 311-324.

4. Whitehead M (2007) A typology of actions to tackle social inequalities in health. J Epidemiol Comminity Health 61, 473-478.

5. Nuffield Council on Bioethics (2007) Public Health: Ethical Issues. http://www.nuffieldbioethics.org/public-health (accessed October 2012).

6. Thaler RH \& Sunstein C (2008) Nudge: Improving Decisions about Health, Wealth and Happiness. New Haven, CT: Yale University Press.

7. Bonell C, McKee M, Fletcher A et al. (2011) Nudge smudge: UK Government misrepresents 'nudge'. Lancet 377, 2158-2159.

8. Marteau TM, Ogilvie D, Roland M et al. (2011) Judging nudging: can nudging improve population health? BMJ 342, d228.

9. McLeroy KR, Bibeau D, Steckler A et al. (1988) An ecological perspective on health promotion programs. Health Educ Q 15, 351-377.

10. Bronfenbrenner U (1979) The Ecology of Human Development London: Harvard University Press.

11. Bronfenbrenner U (1986) Ecology of the familiy as a context for human development: research perspectives. Dev Psychol 22, 723-742.

12. Moore SN, Murphy S \& Moore L (2011) Health improvement, nutritional behaviour and the role of school meals: the usefulness of a socio-ecological perspective to inform policy design, implementation and evaluation. Crit Public Health 21, 441-454.

13. World Health Organization (1986) The Ottawa Charter for Health Promotion. Copenhagen: WHO Regional Office for Europe.

14. World Health Organization (2009) What is a health promoting school? http://www.who.int/school_youth_ health/gshi/hps/en/ (accessed September 2009).

15. Lister-Sharp D, Chapman S, Stewart-Brown S et al. (1999) Health promoting schools and health promotion in schools: two systematic reviews. Health Technol Assess 3, issue $22,1-207$.

16. Mukoma W \& Flisher AJ (2004) Evaluations of health promoting schools: a review of nine studies. Health Promot Int 19, 357-368.

17. Stronach I, Corbin P, McNamara O et al. (2002) Towards an uncertain politics of professionalism: teacher and nurse identities in flux. J Educ Policy 7, 110-138.

18. Hawe P, Shiell A \& Riley T (2009) Theorising interventions as events in systems. Am J Community Psychol 43, 267-276.

19. Glasgow RE, Vogt TM \& Boles SM (1999) Evaluating the public health impact of health promotion interventions: the RE-AIM framework. Am J Public Health 89, 1322-1327.

20. Pawson R \& Tilley N (1997) Realistic Evaluation. London: SAGE.

21. Bell AC, Simmons A, Sanigorski AM et al. (2008) Preventing childhood obesity: the sentinel site for obesity prevention in Victoria, Australia. Health Promot Int 23, 328-336.

22. Swinburn B \& Egger G (2004) The runaway weight gain train: too many accelerators, not enough brakes. BMJ 329, 736-739.

23. de Groot FP, Robertson NM, Swinburn BA et al. (2010) Increasing community capacity to prevent childhood obesity: challenges, lessons learned and results from the Romp \& Chomp intervention. BMC Public Health 10, 522.

24. de Silva-Sanigorski A, Elea D, Bell C et al. (2011) Obesity prevention in the family day care setting: impact of the Romp \& Chomp intervention on opportunities for children's physical activity and healthy eating. Child Care Health Dev 37, 385-393. 
25. de Silva-Sanigorski AM, Bell AC, Kremer P et al. (2010) Reducing obesity in early childhood: results from Romp \& Chomp, an Australian community-wide intervention program. Am J Clin Nutr 91, 831-840.

26. Millar L, Kremer P, de Silva-Sanigorski A et al. (2011) Reduction in overweight and obesity from a 3-year community-based intervention in Australia: the 'It's Your Move!' project. Obes Rev 12, Suppl. 2, 20-28.

27. Sanigorski AM, Bell AC, Kremer PJ et al. (2005) Reducing unhealthy weight gain in children through community capacity-building: results of a quasi-experimental intervention program, Be Active Eat Well. Int J Obes (Lond) 32 , 1060-1067.

28. Herbert J, Moodie M, de Silva-Sanigorski A et al. (2010) The cost-effectiveness of a successful community-based obesity prevention program; the Be Active Eat Well Program. Obes Res Clin Pract $\mathbf{4}, 2$.

29. Moore SN, Murphy S, Tapper K et al. (2010) The social, physical and temporal characteristics of primary school dining halls and their implications for children's eating behaviours. Health Educ 110, 399-411.
30. Moore SN, Murphy S, Tapper K et al. (2010) From policy to plate: barriers to implementing healthy eating policies in primary schools in Wales. Health Policy $\mathbf{9 4}$ 239-245.

31. Moore SN, Tapper K \& Murphy S (2010) Feeding strategies used by primary school meal staff and their impact on children's eating: an opportunity for repeated taste exposure. J Hum Nutr Diet 23, 78-84.

32. Townsend N, Murphy S \& Moore L (2011) The more schools do to promote healthy eating, the healthier the dietary choices by students. J Epidemiol Community Health 65, 889-895.

33. Townsend N \& Foster C (2011) Developing and applying a socio-ecological model to the promotion of healthy eating in the school. Public Health Nutr (Epublication ahead of print version).

34. Moore L \& Tapper K (2008) The impact of school fruit tuck shops and school food policies on children's fruit consumption: a cluster randomised trial of schools in deprived areas. J Epidemiol Community Health 62, 926-931. 